\title{
THE UNCERTAINTY EFFECT: WHEN A RISKY PROSPECT IS VALUED LESS THAN ITS WORST POSSIBLE OUTCOME*
}

\author{
URI GNEEZY \\ JoHN A. LIST \\ GEORGE WU
}

\begin{abstract}
Expected utility theory, prospect theory, and most other models of risky choice are based on the fundamental premise that individuals choose among risky prospects by balancing the value of the possible consequences. These models, therefore, require that the value of a risky prospect lie between the value of that prospect's highest and lowest outcome. Although this requirement seems essential for any theory of risky decision-making, we document a violation of this condition in which individuals value a risky prospect less than its worst possible realization. This demonstration, which we term the uncertainty effect, draws from more than 1000 experimental participants, and includes hypothetical and real pricing and choice tasks, as well as field experiments in real markets with financial incentives. Our results suggest that there are choice situations in which decision-makers discount lotteries for uncertainty in a manner that cannot be accommodated by standard models of risky choice.
\end{abstract}

From the time of Bernoulli on, it has been common to argue that (a) individuals tend to display aversion to the taking of risks, and (b) that risk aversion in turn is an explanation for many observed phenomena in the economic world [Arrow 1971, p. 90].

\section{INTRODUCTION}

Most important decisions involve risk. Thus, it is not surprising that a substantial body of research has tried to understand how decision-makers incorporate risk into their choices. Indeed, risk aversion has played an essential role in helping to understand economic problems as diverse as insurance, contracting, and portfolio selection (e.g., Arrow [1971], Grossman and Hart [1983], and Markowitz [1959]). Most models of risky choice, whether normative or descriptive, assume that individuals value a risky prospect or lottery by some type of weighted average scheme, thereby balancing the possibility of relatively good outcomes with the possibility of relatively poor outcomes. In the classical treatment of decision-making under risk, expected utility theory, that balance is captured by a formulation in which the utility of an outcome is weighted by the probability of that outcome occurring. Prospect theory also imposes a weighted average scheme, in which the utility of an outcome is weighted by a

๑ 2006 by the President and Fellows of Harvard College and the Massachusetts Institute of Technology.

The Quarterly Journal of Economics, November 2006 
decision weight that typically overweights small probabilities and underweights medium to large probabilities [Kahneman and Tversky 1979; Tversky and Fox 1995; Tversky and Kahneman 1992].

The balancing operation invoked in both expected utility theory and prospect theory imposes a basic and fundamental requirement-the value of a risky prospect must lie between the value of that prospect's highest and lowest outcome. Indeed, this requirement, which we call the internality axiom, seems so essential that many empirical measurement procedures preclude violations of this axiom (see, e.g., Gonzalez and Wu [1999]). Contrary to this axiom, individuals in our investigations sometimes value a risky prospect less than its worst possible realization. For example, our experimental participants were willing to pay $\$ 38$ for a restricted $\$ 50$ gift certificate, yet were only willing to pay $\$ 28$ for a lottery ticket that provided an equal chance of that certificate and a $\$ 100$ certificate with the same restrictions. This behavioral result, which we term the uncertainty effect, not only contradicts expected utility and prospect theory but is inconsistent with virtually all models of risky choice. ${ }^{1}$ We demonstrate the uncertainty effect in a series of studies involving hypothetical and real pricing and choice tasks, as well as bidding in auctions in a naturally occurring marketplace. We also identify some necessary conditions for the uncertainty effect and describe an alternative choice process that is consistent with our findings.

Our article is organized as follows. We begin by presenting a graphical description of the uncertainty effect. We then present several demonstrations of the uncertainty effect using a pricing task. We next show the robustness of the uncertainty effect by replicating the pricing results using choice questions. The final set of treatments involves a field experiment that uses auctions

1. See Machina [1987], Camerer [1995], Starmer [2000], and Wu, Zhang, and Gonzalez [2004] for reviews of risky choice models and empirical evidence. Most of these models assume first-order stochastic dominance, a stronger axiom than internality. Regret theory [Bell 1982; Fishburn 1982; Loomes and Sugden 1982] and prospect theory as formalized in Kahneman and Tversky [1979] permit violations of stochastic dominance but prohibit violations of internality (see Birnbaum [1992], Leland [1998], and Tversky and Kahneman [1986] for empirical violations of first-order stochastic dominance). We are aware of two classes of models that in principle permit violations of internality: the disappointment models of Bell [1985] and Loomes and Sugden [1986] (but not Gul [1991]) and models that allow for a "utility of gambling," e.g., Conlisk [1993], Diecidue, Schmidt, and Wakker [2004], Royden, Suppes, and Walsh [1959], and Schmidt [1998] (but not Bleichrodt and Schmidt [2002]). The possibility of the uncertainty effect, however, is not discussed in any of these papers. 


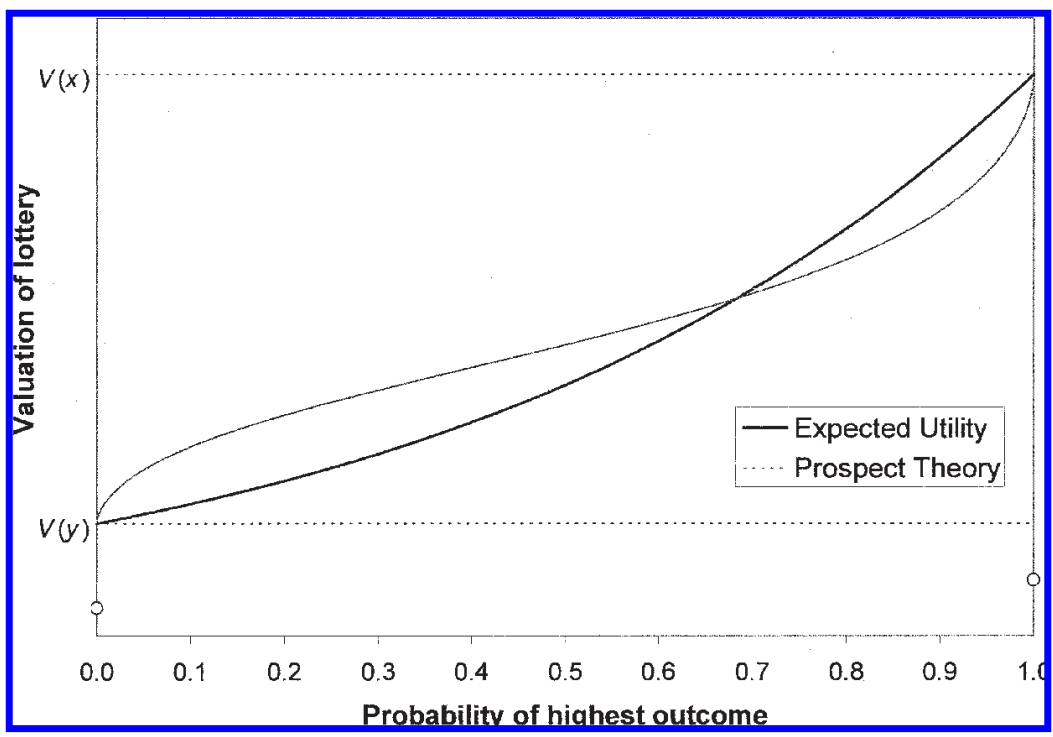

FIGURE I

Valuation of a Risky Prospect for Expected Utility Theory and Prospect Theory

The uncertainty effect of a risky prospect, $(x, p, y)$, is depicted for expected utility theory and prospect theory. The valuation under both models is increasing in the probability of the highest outcome $x$.

conducted in real markets. We conclude with a discussion of what may be driving the uncertainty effect and the implications of the effect for models of risky choice.

\section{The UnCertainty Effect}

The study of risky choice has a long and distinguished history. As noted above, virtually every model of risky choice requires that the value of a risky prospect, whether certainty equivalent, buying price, or selling price, lie between the value of the prospect's highest and lowest outcome. Consider, for example, a lottery, denoted $L=(x, p, y)$, that offers a $p$ chance at $x$ and $1-$ $p$ chance at $y$, where $x>y$. Expected utility, prospect theory, and most other models of risky choice require that $V(x) \geq V(L) \geq V(y)$, where $V(\cdot)$ represents the value of a prospect. We term this requirement the internality axiom. Figure I depicts the internal- 
ity axiom graphically. ${ }^{2}$ The horizontal axis in Figure I represents the probability $p$ of obtaining the higher outcome $x$, and the vertical axis represents the valuation of the prospect-either the certainty equivalent, buying price, or selling price.

The valuation curves begin at $V(y)$ and increase monotonically in $p$ to $V(x)$. For expected utility, the valuation curve is an affine transformation of the inverse of the von Neumann-Morgenstern utility function and hence is convex if the von NeumannMorgenstern utility function is concave. For prospect theory, the valuation curve is typically concave and then convex, reflecting the combination of a concave value function and an inverse S-shaped probability weighting function. Most importantly for our purposes, the curve for both models satisfies the internality axiom - the value of any risky prospect lies between the value of that prospect's highest and lowest outcomes.

\section{PRICing Studies}

Our first empirical exploration of the uncertainty effect involved a series of hypothetical and real pricing tasks. All investigations used a between-subjects experimental design. We present the questions sequentially and then conclude the section with a general discussion of the results. The actual questions used are found in Appendices 1 and 2. All statistical comparisons use the Mann-Whitney test. Participants in all studies in this section were University of Chicago students. Participants in the hypothetical pricing studies were paid $\$ 1$ for answering one question.

\section{III.A. Book Store Gift Certificates}

We begin with a hypothetical pricing question. We asked participants to state their willingness-to-pay (WTP) for either a $\$ 50$ Barnes and Noble gift certificate, a $\$ 100$ Barnes and Noble gift certificate, or one of five lotteries in which they would win either the $\$ 50$ or $\$ 100$ gift certificate. The probabilities of the better prize, the $\$ 100$ gift certificate, were $.99, .60, .50, .40$, and .01. Participants were told that the gift certificate had to be used within the next two weeks. Table I summarizes the results.

The internality axiom requires that the WTP for the five lotteries lie between the WTP for the two certain outcomes. On

2. We thank an anonymous reviewer for suggesting this explication. 
TABLE I

Summary Statistics for Hypothetical Pricing Studies

\begin{tabular}{|c|c|c|c|c|}
\hline \multirow[b]{2}{*}{ Good } & \multicolumn{4}{|c|}{ Willingness-to-pay (dollars) } \\
\hline & Mean & Median & $\begin{array}{l}\text { Standard } \\
\text { deviation }\end{array}$ & $N$ \\
\hline \multicolumn{5}{|l|}{ Barnes and Noble } \\
\hline$\$ 100$ gift certificate $(\mathrm{GC})$ & 45.00 & 40.00 & 27.77 & 31 \\
\hline $\begin{array}{l}99 \text { percent chance at } \$ 100 \mathrm{GC}, \\
1 \text { percent chance at } \$ 50 \mathrm{GC}\end{array}$ & 39.63 & 37.50 & 31.15 & 30 \\
\hline $\begin{array}{l}60 \text { percent chance at } \$ 100 \mathrm{GC} \text {, } \\
40 \text { percent chance at } \$ 50 \mathrm{GC}\end{array}$ & 20.79 & 10.00 & 22.74 & 35 \\
\hline $\begin{array}{l}50 \text { percent chance at } \$ 100 \mathrm{GC} \text {, } \\
50 \text { percent chance at } \$ 50 \mathrm{GC}\end{array}$ & 16.12 & 5.00 & 17.64 & 29 \\
\hline $\begin{array}{l}40 \text { percent chance at } \$ 100 \mathrm{GC} \text {, } \\
60 \text { percent chance at } \$ 50 \mathrm{GC}\end{array}$ & 16.00 & 6.00 & 20.87 & 35 \\
\hline $\begin{array}{l}1 \text { percent chance at } \$ 100 \mathrm{GC} \text {, } \\
99 \text { percent chance at } \$ 50 \mathrm{GC}\end{array}$ & 29.70 & 37.50 & 20.16 & \\
\hline$\$ 50$ gift certificate & 26.10 & 25.00 & 14.75 & 31 \\
\hline \multicolumn{5}{|l|}{ Time Preference } \\
\hline$\$ 200$ in one year & 68.1 & 50.0 & 50.8 & 36 \\
\hline $\begin{array}{l}50 \text { percent chance at } \$ 100 \text { in one } \\
\text { year, } 100 \text { percent chance at } \\
\$ 200 \text { in }\end{array}$ & & & & \\
\hline $\begin{array}{l}\$ 200 \text { in one year } \\
\$ 100 \text { in a year }\end{array}$ & $\begin{array}{l}32.5 \\
43.6\end{array}$ & $\begin{array}{l}12.5 \\
50.0\end{array}$ & $\begin{array}{l}38.4 \\
28.3\end{array}$ & $\begin{array}{l}36 \\
36\end{array}$ \\
\hline & \multicolumn{4}{|c|}{ Willingness-to-work (minutes) } \\
\hline Compensation & Mean & Median & $\begin{array}{l}\text { Standard } \\
\text { deviation }\end{array}$ & $N$ \\
\hline \multicolumn{5}{|l|}{ Boring Task } \\
\hline$\$ 50$ & 150.7 & 120.0 & 108.1 & 32 \\
\hline Lottery between $\$ 25$ and $\$ 50$ & 77.8 & 60.0 & 68.4 & 31 \\
\hline$\$ 25$ & 110.7 & 90.0 & 73.4 & 31 \\
\hline
\end{tabular}

the contrary, we found that the average WTP for the even chance lottery ( $M=16.1$ ) was significantly lower than the average WTP for the $\$ 50$ gift certificate $(M=26.1)(z=2.53, p<.05)$. We also observed the uncertainty effect for the $40 / 60$ lottery $(M=16.0$, $z=3.18, p<.01)$ and the 60/40 lottery $(M=20.8, z=1.94, p<$ $.06)$, but not for the positively skewed $1 / 99$ lottery $(M=29.7)$ or the negatively skewed 99/1 lottery $(M=39.6)$.

Figure II provides a graphical depiction of the willingnessto-pay for the two sure things and five lotteries. The data reveal an interesting pattern. Unlike the monotonically increasing func- 


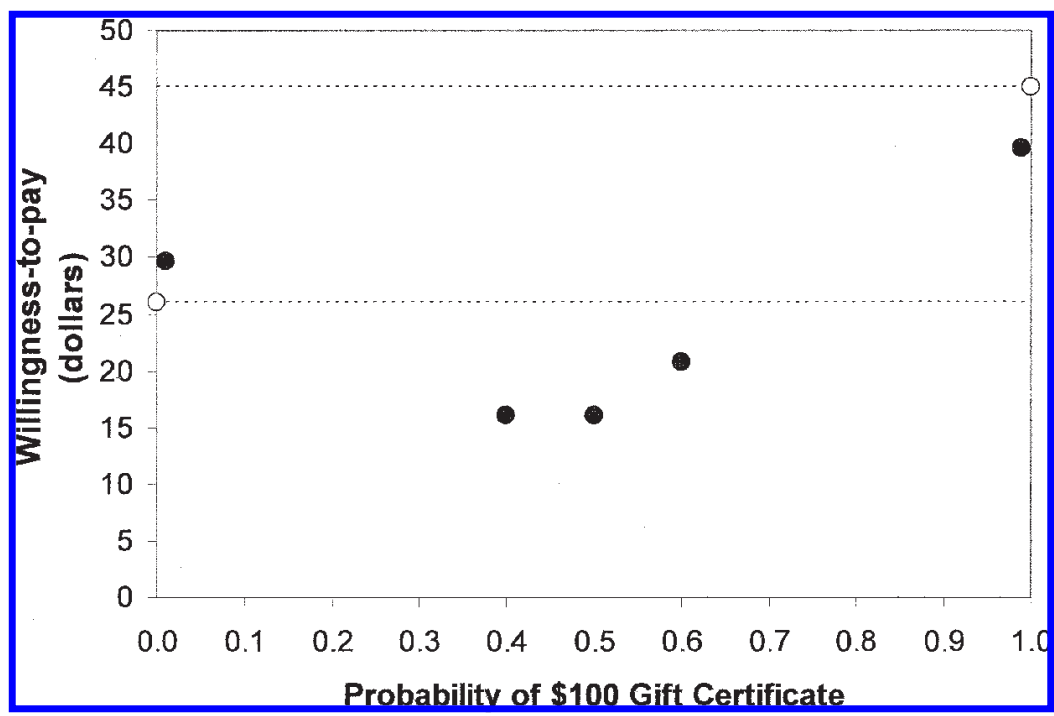

FIGURE II

Willingness-to-Pay (in Dollars) for Gift Certificate Lotteries

Mean willingness-to-pay (in dollars) for various hypothetical lotteries that offer a $p$ chance at a $\$ 100$ Barnes \& Noble gift certificate and a $1-p$ chance at a $\$ 50$ Barnes \& Noble gift certificate. The open circles indicate sure things or degenerate lotteries, a $\$ 50$ gift certificate for sure (0 percent) and a $\$ 100$ gift certificate for sure (100 percent). The filled circles indicate nondegenerate lotteries.

tions in Figure I corresponding to the standard models of risky choice, we find a pattern that is noncontinuous and nonmonotonic over the probability interval. The function only rises above the valuation of the prospect's lowest outcome above $p=.6$ and does not become monotonic until $p \approx .4$ or .5 .

This demonstration of the uncertainty effect represents a direct contradiction of the internality axiom. We examined the robustness of this demonstration by running a variant conducted for real stakes. Participants were again University of Chicago students, who were paid $\$ 3$ for participating in this study plus an opportunity to receive some combination of cash and gift certificates. We used a random-lottery incentive procedure (see, e.g., Starmer and Sugden [1991]). Five percent of the participants had their choices played out for real, in which case we also provided them with $\$ 100$ in cash to use for paying for either the gift certificates or lotteries.

Participants were randomly assigned to one of three condi- 
TABLE II

Summary Statistics for Real-Stakes Pricing Studies

\begin{tabular}{lcccc}
\hline \hline \multirow{2}{*}{ Good } & \multicolumn{3}{c}{ Willingness-to-pay (dollars) } \\
\cline { 2 - 5 } & Mean & Median & $\begin{array}{c}\text { Standard } \\
\text { deviation }\end{array}$ & $N$ \\
\hline $\begin{array}{l}\text { Book Store } \\
\$ 100 \text { gift certificate (GC) }\end{array}$ & 66.15 & 69.00 & 24.28 & 20 \\
50 percent chance at \$100 GC, & & & & \\
$\quad 50$ percent chance at $\$ 50$ & & & & \\
$\quad$ GC & 28.00 & 25.00 & 16.73 & 20 \\
$\$ 50$ gift certificate (GC) & 38.00 & 40.00 & 9.86 & 20 \\
\hline \hline
\end{tabular}

tions. Individuals provided a maximum WTP or buying price for either (i) a $\$ 50$ gift certificate to a local bookstore; (ii) a $\$ 100$ gift certificate to the same local bookstore; or (iii) a lottery in which they were equally likely to receive either the $\$ 50$ or $\$ 100$ gift certificate $\left(n=20\right.$ for each condition) ${ }^{3}$ Buying prices $(x)$ were elicited using an incentive-compatible Becker, DeGroot, and Marschak [1964] mechanism. We placed a sealed envelope containing a randomly determined offer $y$ in front of each individual. Participants were told that they would buy the respective prize at $y$ if and only if $x \geq y$. Complete instructions are found in Appendix 2.

The results of the real-stakes study replicated the hypothetical study (see Table II). The average WTP for the $\$ 50$ gift certificate $(M=38.0)$ was significantly higher than that for the lottery offering an even chance at a $\$ 50$ or $\$ 100$ gift certificate $(M=28.0$, $z=2.30, p<.03$ ).

\section{III.B. Time Preference}

Our second exploration had the same basic structure as the gift certificate study, but involved intertemporal choice. Each participant provided a WTP for either $\$ 100$ received in one year, $\$ 200$ received in one year, or a lottery that paid either $\$ 100$ or $\$ 200$ in one year, with equal probability. Results are summarized in Table I.

The time preference questions revealed the same pattern as

3. We were unable to offer gift certificates to Barnes \& Noble, because Barnes \& Noble was unwilling to provide gift certificates with an expiration date. The smaller local bookstore was chosen because we wanted the participants to discount the value of the gift certificate below its face value. 
the gift certificate questions: the average WTP for the lottery $(M=32.5)$ was significantly less than the average WTP for the lowest outcome of that lottery, $\$ 100$ received in one year $(M=$ 43.6) $(z=2.17, p<.05)$.

\section{III.C. Boring Task}

Our final investigation in this section followed the structure of the first two examples, but used monetary outcomes and a different dependent measure. We asked participants to consider "a boring and tedious task." Participants were then asked: "What is the longest amount of time you would be willing to spend on this task for this payment?" Individuals thus provided a "willingness-to-work" in minutes. The payment for the hypothetical task was either $\$ 25, \$ 50$, or a lottery that offered $\$ 25$ or $\$ 50$, with equal probability. Table I summarizes the results.

Although the dependent measure in this example was nonmonetary, we found the same violation of internality observed in the previous two demonstrations. Participants were willing to work significantly less for the lottery between $\$ 25$ and $\$ 50(M=$ $77.8)$ than for the sure $\$ 25(M=110.7)(z=2.84, p<.01)$.

\section{III.D. Discussion}

The data presented in this section show a systematic violation of the internality axiom. Let $L=(x, p, y)$ denote a lottery that gives a $p$ chance of $x$ and $1-p$ chance of $y$, where $x>y$. The internality axiom requires that $W T P(x) \geq W T P(L) \geq W T P(y)$. In the three demonstrations presented in this section, we observed a contrary pattern: $W T P(y)>W T P(L) .{ }^{4}$ It is important to note that we observed the expected monotonicity for certain outcomes: in all cases, $\operatorname{WTP}(x)$ was significantly higher than $W T P(y)$, where $x>y$.

These demonstrations have two essential conditions. First, our studies all involved between-subject tests. The internality axiom is so transparent and compelling that we expect participants to obey internality in a within-subject test [MacCrimmon and Larsson 1979]. Indeed, we conducted a within-subject investigation in which participants provided a hypothetical WTP for three of the Barnes and Nobles gift certificate treatments-the $\$ 50$ gift certificate, the $\$ 100$ gift certificate, and a 50/50 lottery

4. The last example uses willingness-to-work instead of willingness-to-pay, but the logic is identical. For simplicity, we refer only to WTP. 
between the $\$ 50$ and $\$ 100$ gift certificates. As expected, 29 of our 30 participants priced the three objects in line with the internality axiom.

Second, respondents in our studies had to translate from the lottery currency to the pricing currency. In the first example, it is necessary to translate gift certificates into a monetary value. (We obscured the translation by giving the gift certificates an expiration date.) In the second example, the delayed monetary payments must be converted to a present monetary value. In the final example, monetary outcomes must be translated into time units. To see why this is essential for producing the uncertainty effect, note that respondents do not violate internality when asked to price a lottery that gives $\$ 50$ or $\$ 100$, with equal probability (see, e.g., Birnbaum et al. [1992]). So why do they violate internality when gift certificates are substituted for cash?

We believe that respondents follow a process that differs from that envisaged by either expected utility theory or prospect theory. Consider an individual asked to state her WTP for a lottery that gives equal chance of a $\$ 50$ or $\$ 100$ gift certificate. These models suggest a process in which individuals assign a value to the $\$ 50$ gift certificate (say $\$ 25$ ), assign a value to the $\$ 100$ gift certificate (say $\$ 45$ ), and then price the lottery that offers $\$ 25$ or $\$ 45$ with equal probability. In other words, individuals value the lottery by balancing the possibility of a better outcome with the possibility of a worse outcome. Of course, internality would be satisfied if participants consistently converted all nonmonetary outcomes to monetary equivalents in this manner and then provided a WTP for the constructed cash lottery. Evidently, participants did not use such a process to value the risky prospects investigated in this section.

We suggest that the data presented in this section and depicted graphically in Figure II can be accommodated by a simple model in which decision-makers "code" a lottery in terms of "risk" and "return" and then value the coded lottery. To see how this process is compatible with our results, we apply this process qualitatively to our lotteries. An individual posed with a lottery that involves equal chance at a $\$ 50$ and $\$ 100$ gift certificate might code this lottery as "a $\$ 75$ gift certificate plus some risk." She might then assign a value to a $\$ 75$ gift certificate (say $\$ 35$ ), and then reduce this amount (to say $\$ 15$ ) to account for the uncertainty. Note that this process imposes only a modest constraint on the size of the "risk premium," and thus the resulting WTP could 
well be lower than the WTP that she would have assigned to a riskless $\$ 50$ gift certificate (say $\$ 25$ ) in isolation. In contrast, a lottery that offers a .99 chance of a $\$ 50$ gift certificate and a .01 chance of a $\$ 100$ gift certificate might be coded as "a $\$ 50$ gift certificate plus some upside risk." As a result, this lottery would be valued higher than a sure $\$ 50$ gift certificate (in accord with the internality axiom) and thus higher than the equal chance lottery (in violation of first-order stochastic dominance). We provide a more general discussion of this alternative decision-making process in the epilogue.

\section{Choice Studies}

In this section we investigate the robustness of the uncertainty effect by using choice as a dependent measure. To do so, we conducted a variation of the pricing studies using choice. Recall that internality requires that the value of a lottery $L$ between $x$ and $y, x>y$, exceed the value of $y$. Since we expect individuals to prefer $L$ to $y$ in direct choice, we show the uncertainty effect using an indirect choice paradigm. We introduce a third outcome $z$ and ask one set of respondents to choose between $L$ and $z$ and a second set of respondents to choose between $y$ and $z$. More formally, let $P(A, B)$ be the proportion of time option $A$ is chosen over option $B$. In terms of stochastic choice models (e.g., Luce and Suppes [1965]), $P(A, B)>.5$ is interpreted as $u(A)>u(B)$, where $u()$ denotes the utility of an alternative. Internality requires that $P(L, z) \geq P(y, z)$ for any alternative $z .^{5}$

As before, all treatments were between-subject, and all participants in the hypothetical treatments were University of Chicago undergraduates who were paid $\$ 1$ to answer one question. The actual questions are found in Appendices 3 and 4. Statistical comparisons employ a binomial test.

\section{IV.A. Barnes and Noble Gift Certificate}

We adapted the Barnes and Noble gift certificate demonstration using our indirect choice paradigm. We first consider our hypothetical choice questions. Participants were given a choice either between $\$ 25$ in cash and a $\$ 50$ gift certificate (Sure Thing

5. The necessary condition for this interpretation is some form of regularity. For example, substitutability requires that $U(y)>U(L)$ if $P(y, z)>P(L, z)$ for any $z$ [Tversky and Russo 1969]. 
Condition, $n=28$ ), or between $\$ 25$ in cash and a lottery that offered a $\$ 50$ or $\$ 100$ gift certificate with equal probability (Uncertainty Condition, $n=28$ ). Internality requires that the percentage of respondents choosing $\$ 25$ in cash be higher in the Sure Thing Condition than in the Uncertainty Condition. The results of the previous section suggest the opposite pattern. Indeed, the percentage of respondents preferring the sure cash over the gift certificate option was 21 percent in the Sure Thing Condition and 57 percent in the Uncertainty Condition $(z=2.74, p<.01)$, a pattern inconsistent with the internality axiom and in accord with the uncertainty effect.

We replicated these results using a choice between real gift certificates and cash. The studies were conducted at The Technion in Israel. The Sure Thing Condition $(n=37)$ involved a choice between 100 shekels in cash or a 200 shekel gift certificate at The Technion book store. Participants in the Uncertainty Condition $(n=43)$ chose between a sure 100 shekels in cash or a lottery which offered a 50 percent chance at a 200 shekel gift certificate and a 50 percent chance at a 400 shekel gift certificate. We employed a random-lottery incentive mechanism, in which one participant in each condition had his or her choice played out for real.

In accord with our hypothetical choice demonstration of the uncertainty effect, we found that a significantly higher proportion of participants chose the sure thing in the Uncertainty Condition (74 percent) than in the Sure Thing Condition (43 percent, $z=$ $2.84, p<.01)^{6}$

\section{IV.B. Time Preference}

We adapted the time preference question from Section III in a similar manner. Participants chose either between $\$ 60$ immediately or $\$ 100$ in one year (Sure Thing Condition, $n=72$ ), or between $\$ 60$ immediately and a lottery that offered $\$ 100$ or $\$ 200$ in one year, with equal probability (Uncertainty Condition, $n=$ 76).

Results from this treatment replicate our previous findings: more participants chose the $\$ 60$ cash option when the other prize was a lottery ( 47 percent) than when the other prize was a sure thing (32 percent). The difference between the choice percentages

6. The exchange rate at the time of the study (July 2005) was approximately 4.55 shekels to one US dollar, or roughly $\$ 22$ to 100 shekels. 
in the Sure Thing and Uncertainty Conditions was nearly statistically significant at conventional levels $(z=1.92, p=.055)$, again providing evidence of an indirect choice violation of the internality axiom.

\section{IV.C. Boring Task}

Finally, we modified the boring task study for the indirect choice paradigm. Participants in the Sure Thing Condition $(n=$ 80 ) were told that their payment for the task would be $\$ 25$, while payment for participants in the Uncertainty Condition $(n=78)$ was a lottery that offered $\$ 25$ or $\$ 50$, with equal probability. Participants in both conditions were asked whether they would be "willing to work 90 minutes in exchange for this compensation."

The majority of participants in both conditions indicated a willingness to work for the compensation provided. The percentage of participants who would not be willing to work in the Uncertainty Condition (26 percent), however, was significantly higher than in the Sure Thing Condition (11 percent) $(z=2.34$, $p<.05$ ), consistent with the uncertainty effect.

\section{IV.D. Discussion}

Our choice studies exhibited the same pattern as the pricing studies presented in the previous section. We used an indirect choice paradigm to gauge preference for a lottery and the lottery's worst outcome. Relative to the third alternative, the choice percentage of the lottery was lower than the choice percentage of the lottery's worst outcome. ${ }^{7}$

Decision researchers have found that preferences revealed by choice and pricing do not always agree. Most notably, Lichtenstein and Slovic [1917] demonstrated a preference reversal in which participants priced one gamble higher than a second gam-

7. The questions in the section involved a small shift in wealth relative to the pricing questions. In the pricing questions in Section III, we asked for buying prices rather than certainty equivalents. Of course, the internality axiom requires that the certainty equivalent (respectively, buying price) of a lottery exceed the certainty equivalent (respectively, buying price) of a lottery's lowest prize. For expected utility, the certainty equivalent for a lottery, $(x, p, y)$, is $C E=u^{-1}[p u(x)+$ $(1-p) u(y)$ ], whereas the willingness-to-pay $W T P$ is obtained by solving the implicit equation $p u(x-W T P)+(1-p) u(y-W T P)=u(0)$ for WTP, where $u(\cdot)$ is the von Neumann-Morgenstern utility function. Both $C E$ and WTP are monotonically increasing in $p$ as long as $u(\cdot)$ is monotonically increasing. We thank an anonymous reviewer for urging us to be more explicit about the method of valuing lotteries in each case. 
ble, but preferred the second gamble to the first gamble in direct choice (see also Grether and Plott [1979] and Slovic and Lichtenstein [1983]). More generally, Kahneman, Ritov, and Schkade [1999] have suggested that pricing is often sensitive to features of the problem presentation that are normatively irrelevant and insensitive to aspects that are normatively essential (e.g., Boyle et al. [1994]). The empirical results in this section, however, indicate that the uncertainty effect is not unique to pricing, but extends to choice situations as well. ${ }^{8}$

\section{Treatments in the Marketplace}

Although the results described above paint a picture that some may consider compelling, some economists have been slow to accept anomalous findings, partly because some studies suggest that certain behavioral tendencies are attenuated in market settings (e.g., Chu and Chu [1990] and List [2003]). To provide evidence of whether the uncertainty effect occurs in the marketplace, we look at bidding behavior in incentive-compatible auctions on the floor of a sportscard show.

The sportscard marketplace is a natural setting for an examination of preferences, as it provides a rich pool of participants making decisions in a familiar environment, while also providing natural variation of expertise. The field experiment was carried out on the floor of various sportscard shows in Chantilly, Virginia, in 2003. Each participant's experience typically followed three steps: (1) inspection of the goods, (2) learning the rules, and (3) conclusion of the transaction. In Step 1, a potential subject approached the experimenter's table and inquired about the sale of the baseball card displayed on the table. The experimenter then invited the potential subject to take about five minutes to participate in an experiment (auction). If the participant accepted the invitation, then he was allocated to one of ten treatments.

We summarize the experimental design in Table III. The setup of the field experimental design is similar to the studies presented in the previous treatments: in six treatments (three hypothetical and three actual), we used a "superior" good, "inferior" good, and a 50/50 lottery between the two (rows 1, 2, and 4

8. We speculate that there also might be an extension of the uncertainty effect for decision under uncertainty. In future research, we hope to explore the parallels between findings such as the Ellsberg paradox and the phenomena documented here. 


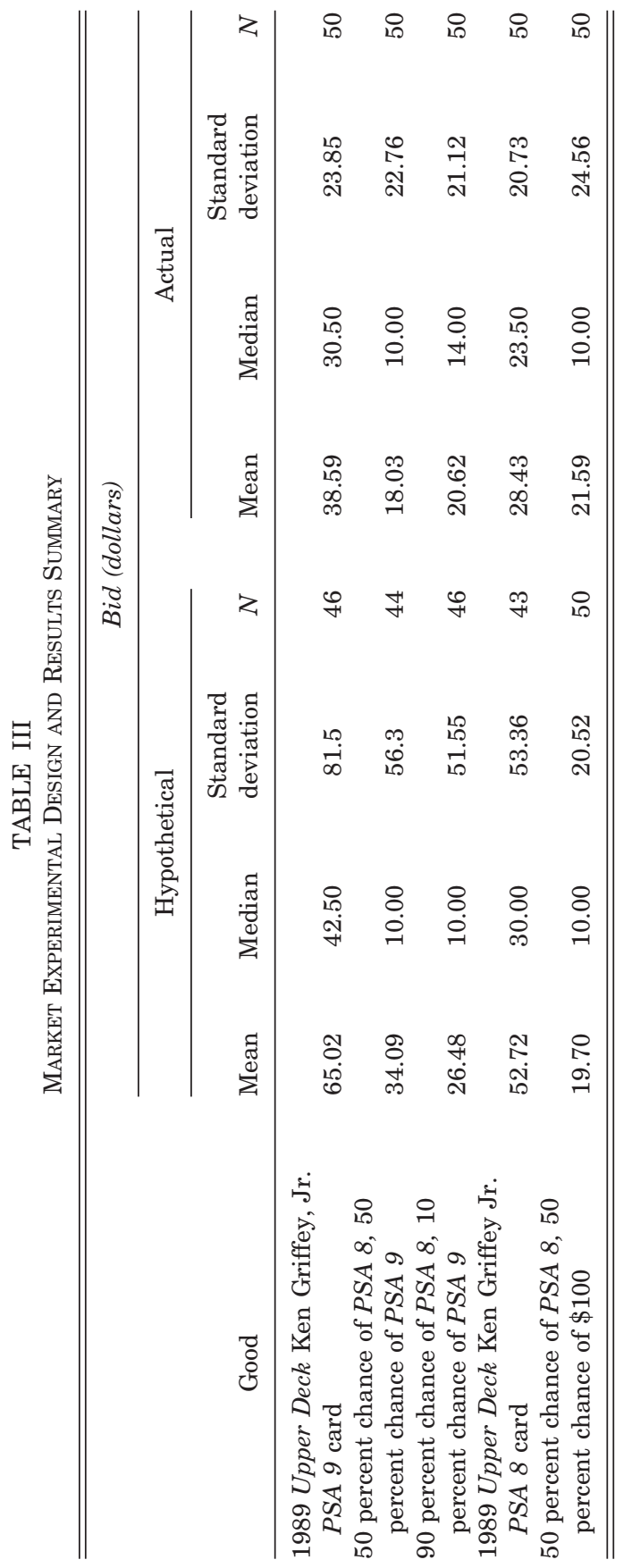


of Table III). To provide variation in the quality of the goods, we used the grading system of a well-known third party, Professional Sports Authenticators (PSA). ${ }^{9}$ The "superior" good was a Ken Griffey, Jr. 1989 Upper Deck baseball card graded "Mint 9" by PSA, and the "inferior" good was an otherwise identical variant, but graded "Near Mint 8" by PSA. The PSA 8 card was identical to the PSA 9, but for slight fraying on one corner. This difference in quality maps into a difference of $\$ 60$ in "book value"-the PSA 9 card had a book value of $\$ 100$ whereas the PSA 8 "booked" for $\$ 40$.

The other four treatments represented variations of the lotteries used in sections III and IV. In two treatments (row 3 in Table III), we used a positively skewed lottery with a 90 percent chance of winning the PSA 8 card and a 10 percent chance of winning the PSA 9 card. In the final two treatments (row 5 in Table III), the lottery was an equal chance of receiving the PSA 8 card or $\$ 100$ in cash. The cash prize was chosen to be equivalent to the book price of the PSA 9 card.

In Step 2 of the experiment, the participant learned the allocation rules. For example, following the hypothetical treatments with the student participants, we had participants answer the following type of question (this is verbatim the question from the PSA 9 hypothetical exercise; Appendix 5 includes complete instructions for the PSA 9 auction):

Imagine that you have the opportunity to purchase the baseball card on the table: the 1989 Upper Deck Ken Griffey Jr. PSA 9 card.

How much would you pay for the card here and now? \$

The other four hypothetical treatments were similar in structure.

Our allocation mechanism was a Vickrey [1961] second-price auction, an auction that has proved straightforward in other field experiments (see, e.g., List [2001]). Finally, in Step 3 the experimenter explained that the participant should return at 5 P.M. on Sunday to find out the auction results. If a participant did not return for the specified transaction time, she would be contacted and would receive her card in the mail (postage paid by the experimenter) within three days of receipt of her payment.

9. PSA, which grades cards on a $1-10$ scale (10 being the best card), is the world's largest sportscard grading and authentication service, currently accepting over 300,000 trading cards per month for grading. PSA is the most widely accepted grading standard in the sportscard market, and maintains co-branded grading and authentication sites with eBay, Yahoo, and other online commerce and content sites. The first card ever graded by PSA was the famous T206 Honus Wagner card that sold for $\$ 1.2$ million in 2000 . 
Before proceeding to the results summary, we mention a few noteworthy aspects of the experimental design. First, no participant participated in more than one treatment, hence the design was between-subject as in the treatments discussed earlier. Second, if the individual agreed to participate, she could pick up and visually examine each card (in sealed cardholders, with the graded card condition clearly marked). The experimenter worked one-on-one with the participant, and imposed no time limit on her inspection of the cards. Third, the treatment type was changed at the top of each hour, so each participant's treatment type was determined based on the time they visited the table at the card show.

\section{V.A. Results}

The results of the field experimental data are summarized in Table III. All comparisons are by means of a Mann-Whitney test. First, the results of Sections III and IV replicate in the hypothetical treatments in the marketplace: agents valued the 50/50 card lottery $(M=34.09)$ significantly less than they valued the worst possible realization ( $P S A 8, M=52.72, z=2.97, p<.01$ ). The uncertainty effect extended to the two variations, the 10/90 lottery $(M=26.48, z=3.92, p<.001)$, as well as the $50 / 50$ lottery in which we substituted $\$ 100$ for the PSA 9 card $(M=19.70, z=$ $3.81, p<.001$ ).

Next we consider the bids in the actual auction. While the bid level in the actual auctions is lower than in the hypothetical treatments, the uncertainty effect is alive and well in the marketplace: the average bid for the 50/50 lottery of $\$ 18.03$ is significantly lower than the average bid for the PSA 8 auction of $\$ 28.43$ $(z=3.31, p<.001)$. The uncertainty effect also extended to the $10 / 90$ lottery $(M=20.62, z=2.72, p<.01)$ as well as to the lottery with a cash prize of $\$ 100(M=21.59, z=2.58, p<.01)$.

Finally, note that the average bid for the positively skewed $10 / 90$ lottery of $\$ 20.62$ was higher, although not significantly so, than the average bid of the stochastically dominating 50/50 lottery of $\$ 18.03(z=1.55, p=.13)$. We contrast this result to our earlier pricing study, where we found that a more extremely positively skewed lottery was priced higher than both the lottery's worst outcome and the stochastically dominating 50/50 lottery. We depict these results in Figure III. 


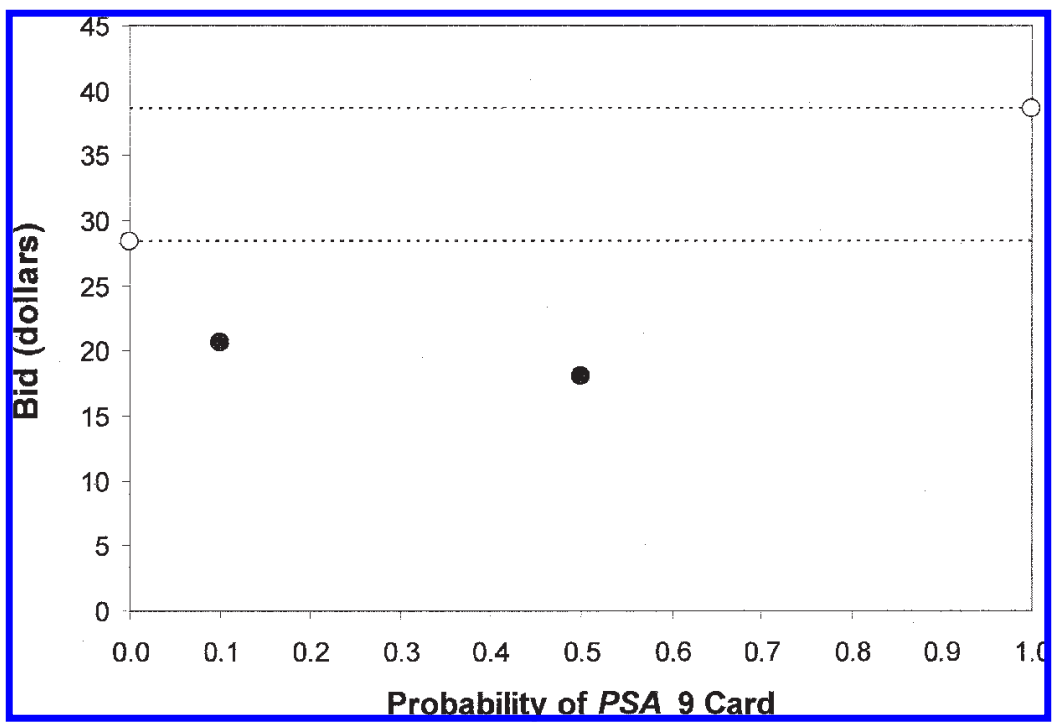

FiguRe III

Bids (in Dollars) for Ken Griffey, Jr. Baseball Cards

Mean bids (in dollars) for hypothetical lotteries that offer a $p$ chance at a 1989 Upper Deck Ken Griffey, Jr. PSA 9 card and a $1-p$ chance at a 1989 Upper Deck Ken Griffey, Jr. PSA 8 card. The open circles indicate sure things or degenerate lotteries, a PSA 8 card for sure (0 percent) and a PSA 9 card for sure (100 percent). The filled circles indicate nondegenerate lotteries.

\section{EPILOGUe}

Expected utility theory and prospect theory are based on the same fundamental premise: individuals choose among risky prospects by balancing the value of the possible consequences. Contrary to this premise, we document an uncertainty effect-individuals value a lottery less than the lottery's worst outcome. The uncertainty effect was demonstrated in pricing tasks (the WTP for a lottery was lower than the WTP for the lottery's worst outcome), and choice tasks (relative to a third alternative, the choice percentage for a lottery was lower than the choice percentage for the lottery's worst outcome). We also found the uncertainty effect for real as well as hypothetical choices and in a field experiment using hypothetical as well as actual auctions.

Although the uncertainty effect proved to be robust in our demonstrations, these demonstrations appear to require two es- 
sential conditions. ${ }^{10}$ First, our treatments are all between-subject investigations. The internality axiom is so normatively compelling that it will be followed when the problem presentation suggests that the axiom should be applied. Our between-subject treatments make no such demands on our participants, however. ${ }^{11}$ Expected utility theory and alternatives to expected utility such as prospect theory require a correspondence between choices at hand and other choices that the decision-maker could face. The uncertainty effect suggests that the correspondence between such choices might in some cases be limited.

Second, the objects in our lotteries have a different currency than the pricing currency or the comparison alternative. We discuss two reasons why this is essential. First, the application of internality is transparent and compelling when a decision-maker is asked to price a lottery with a high prize of $\$ 200$ and a low prize of $\$ 100$. Second, the need to translate from one dimension to another dimension increases the cognitive demands on our participants. ${ }^{12}$ For example, Tversky and Shafir [1992] suggested that there is a "loss of acuity induced by uncertainty." In one study, they had respondents consider a lottery that offered an equal chance to win $\$ 200$ or lose $\$ 100$. When asked whether they would take a second identical gamble, most respondents accepted the gamble if they had won the first one, accepted the gamble if they had lost the first one, but rejected the gamble if they did not know whether they had won or lost. More recently, van Dijk and Zeelenberg [2003] found an effect in the spirit of our uncertainty effect: participants were more likely to continue with plans to open a new restaurant when market potential was high (35 percent) than low (15 percent), but were least likely to continue when told that market potential was uncertain and between 15 to 35 percent. In sum, these studies suggest that individuals may find it difficult or unnatural to think through the possible conse-

10. Of course, the uncertainty effect also must be calibrated for the particular subject population. For example, we conducted a pilot of the real-stakes choice experiment at the University of Maryland. However, the parameters were poorly calibrated, and most participants in both conditions preferred the cash to the gift certificates. A more detailed description of this pilot is available upon request.

11. Other researchers have demonstrated related differences between within- and between-subject treatments (e.g., Fox and Tversky [1995], Hsee et al. [1999], Kahneman and Tversky [1996], and Tversky and Shafir [1992]).

12. This insight is consonant with data from our field auctions, which suggest that dealers, who have intense experience with sportscards, do not violate the internality axiom. Our preferred interpretation is that dealers are "coding" the sportscards as money rather than as a good for final consumption. 
quences of a risky choice and that they, as a result, may alter their choice process to deal with the conflict [Shafir 1994; Shafir, Simonson, and Tversky 1993].

Both expected utility theory and prospect theory impose a weighted average scheme, and are thus incompatible with the uncertainty effect. Although these models are unable to accommodate the uncertainty effect, research in this direction has been enormously productive: prospect theory has organized the standard violations of expected utility and predicted new violations of expected utility. Parametric forms for these models have been proposed [Gonzalez and Wu 1999; Tversky and Fox 1995; Tversky and Kahneman 1992], and these models have been used with success in applications (see, e.g., Benartzi and Thaler [1995] and Gneezy and Potters [1997]). Thus, our results should not suggest abandoning expected utility theory or alternatives to expected utility such as prospect theory.

Nevertheless, we do envision a process for incorporating a decision-maker's aversion to risk that departs from both expected utility theory as well as prospect theory. In expected utility theory, risk aversion is modeled by the curvature of the utility function, whereas in prospect theory, risk aversion may also be captured by loss aversion and curvature of the probability weighting function [Tversky and Kahneman 1992; Wakker 1994]. The present research suggests that there are choice situations in which decision-makers discount lotteries for uncertainty in a manner that is difficult to reconcile with standard models.

\section{Appendix 1: Hypothetical Pricing Task Questions}

\section{Barnes and Noble Gift Certificate}

$\$ 50(\$ 100)$ Gift Certificate

Imagine that we offer you a $\$ 50(\$ 100)$ gift certificate for Barnes and Noble. The gift certificate is good for use within the next two weeks. What is the highest amount of money you would be willing to pay for this certificate?

50/50 Lottery

Imagine that we offer you a lottery ticket that gives you a 50 percent chance at a $\$ 50$ gift certificate for Barnes and Noble, and a 50 percent chance at a $\$ 100$ gift certificate for Barnes and Noble. Whichever gift certificate you win is good for use within 
the next two weeks. What is the highest amount of money you would be willing to pay for this lottery ticket?

Positively-skewed Lottery

Imagine that we offer you a lottery ticket that gives you a 99 percent chance at a $\$ 50$ gift certificate for Barnes and Noble, and a 1 percent chance at a $\$ 100$ gift certificate for Barnes and Noble. Whichever gift certificate you win is good for use within the next two weeks. What is the highest amount of money you would be willing to pay for this lottery ticket?

\section{Time preference}

Delayed $\$ 100(\$ 200)$

Imagine that we offer you $\$ 100$ ( $\$ 200)$ one year from today. What is the highest amount of money you would be willing to pay for this now?

Lottery

Imagine that we offer you a lottery that pays $\$ 100$ or $\$ 200$ with equal probability. The amount you earn will be paid to you one year from today. What is the highest amount of money you would be willing to pay for this now?

Boring Task

Sure $\$ 25(\$ 50)$

Consider a boring and tedious task (like sorting file folders). Imagine that your payment for this task is $\$ 25$. What is the longest amount of time you would be willing to spend on this task for this payment? minutes

\section{Lottery}

Consider a boring and tedious task (like sorting file folders). Imagine that your payment for this task is a lottery ticket that will give you $\$ 25$ or $\$ 50$, with equal probability. What is the longest amount of time you would be willing to spend on this task for this payment? minutes

\section{Appendix 2: Real Pricing Task Instructions}

Thank you for participating in our study.

A potential exchange will be described below. Five percent of you will have your response below played out for real. Whether your response is played out for real will be determined by a random draw conducted after you have completed your response. You will receive $\$ 100$ as well if you are randomly selected. 
The potential exchange (Gift Certificates)

Your decision is to state how much you would be willing to pay for a \$50 (\$100) Gift Certificate for the 57th Street Coop. The gift certificate can be used within the next two weeks.

Please indicate a maximum buying price for the $\$ 50(\$ 100)$ gift certificate. If you indicate a maximum buying price of $\mathrm{x}$, you would buy the $\$ 50$ ( $\$ 100$ ) gift certificate if we offered the certificate for a price less than $\mathrm{x}$, and you would not buy the $\$ 50(\$ 100)$ gift certificate if we offered a price greater than $\mathrm{x}$.

The envelope in front of me has a predetermined price offer $y$. After you indicate your buying price, we will randomly select one of you (the person selected is random and is not related to your buying price statement), and then open the envelope.

If the price $y$ is less than or equal to your buying price $x$, then the randomly chosen person will buy the $\$ 50(\$ 100)$ gift certificate (since the price is below your buying price). The price that person would pay is $\mathrm{y}$.

If the price $\mathrm{y}$ is greater than your buying price $\mathrm{x}$, then you will not buy the $\$ 50(\$ 100)$ gift certificate (since the price is above your buying price). It is best under this system for you to provide your true maximum buying price: the highest amount of money that you would be willing to pay for the $\$ 50(\$ 100)$ gift certificate.

The potential exchange (Lottery)

Your decision is to state how much you would be willing to pay for a lottery ticket that gives you a 50 percent chance at a $\$ 50$ gift certificate for the 57th Street Coop, and a 50 percent chance at a $\$ 100$ gift certificate for the 57th Street Coop. Whichever gift certificate you win is good for use within the next two weeks. We will flip a coin to determine which prize you get. If the coin comes up heads, you will get the $\$ 50$ gift certificate. If the coin comes up tails, then you will get the $\$ 100$ gift certificate.

Please indicate a maximum buying price for the lottery ticket. If you indicate a maximum buying price of $\mathrm{x}$, you would buy the lottery ticket if we offered it for a price less than $\mathrm{x}$, and you would not buy the lottery ticket if we offered a price greater than $\mathrm{x}$.

The envelope in front of me has a predetermined price offer $y$. After you indicate your buying price, we will randomly select one of you (the person selected is random and is not related to your buying price statement), and then open the envelope.

If the price $y$ is less than or equal to your buying price $x$, then the randomly chosen person will buy the lottery ticket (since the 
price is below your buying price). The price that person would pay is $\mathrm{y}$.

If the price $\mathrm{y}$ is greater than your buying price $\mathrm{x}$, then you will not buy the lottery ticket (since the price is above your buying price). It is best under this system for you to provide your true maximum buying price: the highest amount of money that you would be willing to pay for the lottery ticket.

\section{Appendix 3: Hypothetical Choice Task Questions}

\section{Barnes and Noble Gift Certificate}

Sure Thing Condition (Sure $\$ 50$ gift certificate)

Imagine that you were given the following choice. Indicate which option you would select.

- a $\$ 50$ gift certificate for Barnes and Noble. The gift certificate can be used any time within the next two weeks.

$-\$ 25$ in cash.

Uncertainty Condition

Imagine that you were given the following choice. Indicate which option you would select.

- a lottery that pays $\$ 50$ or $\$ 100$, with equal probability, in the form of a gift certificate for Barnes and Noble. The gift certificate can be used any time within the next two weeks.

- \$25 in cash.

Time preference

Sure Thing Condition ( $\$ 60$ immediately)

Imagine that you were given the following choice. Indicate which option you would select.

- $\$ 100$, payable one year from now.

- $\$ 60$, payable immediately.

Uncertainty Condition

Imagine that you were given the following choice. Indicate which option you would select.

- A lottery that pays either $\$ 100$ or $\$ 200$ with equal probability, payable one year from now.

— $\$ 60$, payable immediately.

Boring Task

Sure Thing Condition (Sure \$25)

Consider a boring and tedious task (like sorting file folders). 
Imagine that your payment for this task is $\$ 25$. Would you be willing to work 90 minutes in exchange for this compensation?

Uncertainty Condition

Consider a boring and tedious task (like sorting file folders). Imagine that your payment for this task is a lottery ticket that will give you $\$ 25$ or $\$ 50$, with equal probability. Would you be willing to work 90 minutes in exchange for this compensation?

\section{Appendix 4: Real Choice Task Instructions}

Note: These instructions were translated from Hebrew into English.

Sure Thing Condition (Sure 100 shekels)

Welcome! In this study we ask that you simply indicate which option you prefer by circling the letter below:

A. a 200 shekel gift certificate for The Technion bookstore. The gift certificate can be used any time within the next two weeks.

B. 100 shekels in cash.

As soon as everyone completes their choice, one of you will be selected at random. If you are selected, you will receive the option that you chose.

Uncertainty Condition

Welcome! In this study we ask that you simply indicate which option you prefer by circling the letter below:

A. a lottery that pays 200 or 400 shekels, with equal probability, in the form of a gift certificate for The Technion book store. The gift certificate can be used any time within the next two weeks.

B. 100 shekels in cash.

As soon as everyone completes their choice, one of you will be selected at random. If you are selected, you will receive the option that you chose. If you chose A (the lottery), then we will resolve the lottery with a coin flip. You win a 200 shekel gift certificate if the coin comes up heads and a 400 shekel gift certificate if it comes up tails.

\section{Appendix 5: Market Auction Instructions}

Welcome to Lister's Auctions! You have the opportunity to bid in an auction for the baseball card on the table. 
The card up for auction is the 1989 Upper Deck Ken Griffey, Jr. PSA 9 card on the table.

Auction Rules: A sealed bid second-price auction will be used to determine the winner. Thus, if your bid of $\$ \mathrm{X}$ is the highest bid and the next highest bid is $\$ \mathrm{X}-5$, you win the card, but only pay $\$ \mathrm{X}-5$. Under this bidding mechanism it is best for you to bid your true reservation value: the largest amount of money that, if you won the auction, you would be comfortable paying for the card here and now. This is so because bidding over this value may cause you to pay too much and bidding under this value decreases your odds of winning the card. Let's now go over an example that shows why bidding your reservation value makes sense.

For example, if the top four bids are ranked highest to lowest as follows:

$\$ \mathrm{~A}$

$\$ \mathrm{~B}$

$\$ \mathrm{C}$

$\$ \mathrm{D}$

the bidder who bid $\$ \mathrm{~A}$ wins the card and pays $\$ \mathrm{~B}$.

Now let's discuss why bidding your true reservation value makes sense.

Would you like to go over another example?

I will accept bids from the first 50 bidders. I will announce the winner of the auction Sunday at 5 PM.

Given that the winner of the card will pay a price equal to the amount of the second-highest bid, please place your bid below:

My bid for the 1989 Ken Griffey Jr. PSA 9 card: $\$$

After the winner pays me cash or check for the card, the card will be awarded to the winner (I pay postage). Please sign on the line below to verify your bid. Also, please provide your name, telephone number, and mailing address below:

Signature_
Name_
Address_-
Phone\#_
Email address__

University of California, SAN Diego

UNIVERSITY OF CHICAGO AND NBER

UNIVERSITY OF CHICAGO 


\section{REFERENCES}

Arrow, Kenneth J., Essays in the Theory of Risk-Bearing (Chicago: Markham Publishing Company, 1971).

Becker, Gordon M., Morris H. DeGroot, and Jacob Marschak, "Measuring Utility by a Single- Response Sequential Method," Behavioral Science, IX (1964), $226-232$

Bell, David E., "Regret in Decision Making under Uncertainty," Operations Research, XXX (1982), 961-981.

, "Disappointment in Decision Making under Uncertainty," Operations Research, XXXIII (1985), 1-27.

Benartzi, Shlomo, and Richard H. Thaler, "Myopic Loss Aversion and the Equity Premium Puzzle," Quarterly Journal of Economics, CX (1995), 75-92.

Birnbaum, Michael H., "Violations of Monotonicity and Contextual Effects in Choice-Based Certainty Equivalents," Psychological Science, III (1992), $310-314$.

Birnbaum, Michael H., Gregory Coffey, Barbara A. Mellers, and Robin Weiss, "Utility Measurement: Configural-Weight Theory and the Judge's Point of View," Journal of Experimental Psychology: Human Perception and Performance, XVIII (1992), 331-346.

Bleichrodt, Han, and Ulrich Schmidt,, "A Context-Dependent Model of the Gambling Effect," Management Science, XLVIII (2002), 802-812.

Boyle, Kevin J., William H. Desvousges, F. Reed Johnson, Richard W. Dunford, and Sara P. Hudson, "An Investigation of Part-Whole Biases in ContingentValuation Studies," Journal of Environmental Economics and Management, XXVII (1994), 64-83.

Camerer, Colin F., "Individual Decision Making," in J. H. Kagel and A. E. Roth, eds., The Handbook of Experimental Economics (Princeton, NJ: Princeton University Press, 1995), pp. 587-703.

$\mathrm{Chu}$, Y. P., and R. L. Chu, "The Subsidence of Preference Reversals in Simplified and Marketlike Experimental Settings: A Note," American Economic Review, LXXX (1990), 902-911.

Conlisk, John, "The Utility of Gambling," Journal of Risk and Uncertainty, VI (1993), 255-275.

Diecidue, Enrico, Ulrich Schmidt, and Peter P. Wakker, "The Utility of Gambling Reconsidered," Journal of Risk and Uncertainty, XXIX (2004), 241-259.

Fishburn, Peter C., "Nontransitive Measurable Utility," Journal of Mathematical Psychology, XXVI (1982), 31-67.

Fox, Craig R., and Amos Tversky, "Ambiguity Aversion and Comparative Ignorance," Quarterly Journal of Economics, CX (1995), 585-603.

Gneezy, Uri, and Jan Potters, "An Experiment on Risk Taking and Evaluation Periods," Quarterly Journal of Economics, CXII (1997), 631-645.

Gonzalez, Richard, and George Wu, "On the Shape of the Probability Weighting Function," Cognitive Psychology, XXXVIII (1999), 129-166.

Grether, David M., and Charles R. Plott, "Economic Theory of Choice and the Preference Reversal Phenomenon," American Economic Review, LXIX (1979), 623-638.

Grossman, Sanford J., and Oliver D. Hart, "An Analysis of the Principal-Agent Problem," Econometrica, LI (1983), 7-46.

Gul, Faruk, "A Theory of Disappointment in Decision Making under Uncertainty," Econometrica, LIX (1991), 667-686.

Hsee, Christopher K., George F. Loewenstein, Sally Blount, and Max H. Bazerman, "Preference Reversals between Joint and Separate Evaluation of Options: A Review and Theoretical Analysis," Psychological Bulletin, CXXV (1999), 576-590.

Kahneman, Daniel, Ilana Ritov, and David Schkade, "Economic Preferences or Attitude Expressions?: An Analysis of Dollar Responses to Public Issues," Journal of Risk and Uncertainty, XIX (1999), 203-235.

Kahneman, Daniel, and Amos Tversky, "Prospect Theory: An Analysis of Decision under Risk," Econometrica, XLVII (1979), 263-291.

Kahneman, Daniel, and Amos Tversky, "On the Reality of Cognitive Illusions," Psychological Review, CIII (1996), 583-591. 
Leland, Jonathan W., "Similarity Judgments in Choice under Uncertainty: A Reinterpretation of the Prediction of Regret Theory," Management Science, XLIV (1998), 659-672.

Lichtenstein, Sarah, and Paul Slovic, "Reversals of Preference between Bids and Choices in Gambling Decisions," Journal of Experimental Psychology, LXXXIX (1971), 46-55.

List, John A., "Do Explicit Warnings Eliminate the Hypothetical Bias in Elicitation Procedures? Evidence from Field Auctions for Sportscards," American Economic Review, XCI (2001), 1498-1507.

_, "Does Market Experience Eliminate Market Anomalies?" Quarterly Journal of Economics, CXVIII (2003), 41-71.

Loomes, Graham, and Robert Sugden, "Regret Theory: An Alternative Theory of Rational Choice under Uncertainty," Economic Journal, XCII (1982), $805-825$.

Loomes, Graham, and Robert Sugden, "Disappointment and Dynamic Consistency in Choice under Uncertainty," Review of Economic Studies, LIII (1986), 271-282.

Luce, R. Duncan, and Patrick Suppes, "Preference, Utility, and Subjective Probability," in R. D. Luce, R. B. Bush, and E. Galanter, eds., Handbook of Mathematical Psychology, Vol. 3 (New York: Wiley, 1965), pp. 249-410.

MacCrimmon, Kenneth R., and Stig Larsson, "Utility Theory: Axioms versus Paradoxes," The Expected Utility Hypothesis and the Allais Paradox, M. Allais and O. Hagen, eds. (Dordrecht, The Netherlands: D. Riedel, 1979), pp. 333-409.

Machina, Mark J., "Choice under Uncertainty: Problems Solved and Unsolved," Journal of Economic Perspectives, I (1987), 121-154.

Markowitz, Harry, Portfolio Selection: Efficient Diversification of Investments (New York: Wiley, 1959).

Royden, Halsey L., Patrick Suppes, and Karol Walsh, "A Model for the Experimental Measurement of the Utility of Gambling," Behavioral Science, IV (1959), 11-18.

Schmidt, Ulrich, "A Measurement of the Certainty Effect," Journal of Mathematical Psychology, XLII (1998), 32-47.

Shafir, Eldar, "Uncertainty and the Difficulty of Thinking through Disjunctions," Cognition, L (1994), 403-430.

Shafir, Eldar, Itamar Simonson, and Amos Tversky, "Reason-Based Choice," Cognition, XLIX (1993), 11-36.

Slovic, Paul, and Sarah Lichtenstein, "Preference Reversals: A Broader Perspective," American Economic Review, LXXIII (1983), 596-605.

Starmer, Chris, "Developments in Non-Expected Utility Theory: The Hunt for a Descriptive Theory of Choice under Risk," Journal of Economic Literature, XXXVIII (2000), 332- 382.

Starmer, Chris, and Robert Sugden, "Does the Random-Lottery Incentive System Elicit True Preferences? An Experimental Investigation," American Economic Review, LXXXI (1991), 971-978.

Tversky, Amos, and Craig R. Fox, "Weighing Risk and Uncertainty," Psychological Review, CII (1995), 269-283.

Tversky, Amos, and Daniel Kahneman, "Rational Choice and the Framing of Decisions," Journal of Business, LIX (1986), S251-S278.

Tversky, Amos, and Daniel Kahneman, "Advances in Prospect Theory: Cumulative Representation of Uncertainty," Journal of Risk and Uncertainty, V (1992), 297-323.

Tversky, Amos, and J. Edward Russo, "Substitutability and Similarity in Binary Choices," Journal of Mathematical Psychology, VI (1969), 1-12.

Tversky, Amos, and Eldar Shafir, "The Disjunction Effect in Choice under Uncertainty," Psychological Science, III (1992), 305-309.

van Dijk, Eric, and Marcel Zeelenberg, "The Discounting of Ambiguous Information in Economic Decision Making," Journal of Behavioral Decision Making, XVI (2003), 341-352.

Vickrey, William, "Counterspeculation, Auctions, and Competitive Sealed Tenders," Journal of Finance, XVI (1961), 8-37. 
Wakker, Peter P., "Separating Marginal Utility and Probabilistic Risk Aversion," Theory \& Decision, XXXVI (1994), 1-44.

$\mathrm{Wu}$, George, Jiao Zhang, and Richard Gonzalez, "Decision under Risk," in Derek J. Koehler and Nigel Harvey, eds. Blackwell Handbook of Judgment and Decision Making (Oxford: Blackwell, 2004), pp. 399-423. 


\section{This article has been cited by:}

1. Shavit Tal, Benzion Uri, Shahrabani Shosh. 2010. Risk attitude in lotteries offering real products and monetary outcomes. International Journal of Economic Theory 6:2, 253-261. [CrossRef]

2. Huan Zhao, Xiaodong Du, David A. Hennessy. 2010. Pass-through in United States beef cattle prices: a test of Ricardian rent theory. Empirical Economics . [CrossRef]

3. Ondřej Rydval, Andreas Ortmann, Sasha Prokosheva, Ralph Hertwig. 2009. How certain is the uncertainty effect?. Experimental Economics 12:4, 473-487. [CrossRef]

4. Gideon Keren, Martijn C. Willemsen. 2009. Decision anomalies, experimenter assumptions, and participants' comprehension: Revaluating the uncertainty effect. Journal of Behavioral Decision Making 22:3, 301-317. [CrossRef]

5. Uri Simonsohn. 2009. Direct Risk Aversion: Evidence From Risky Prospects Valued Below Their Worst Outcome. Psychological Science 20:6, 686-692. [CrossRef]

6. Doron Sonsino. 2008. Disappointment Aversion in internet Bidding-Decisions. Theory and Decision 64:2-3, 363-393. [CrossRef]

7. Marc Oliver Rieger, Mei Wang. 2008. Prospect theory for continuous distributions. Journal of Risk and Uncertainty 36:1, 83-102. [CrossRef]

8. Yoram Amiel, Frank Cowell, Liema Davidovitz, Avraham Polovin. 2008. Preference reversals and the analysis of income distributions. Social Choice and Welfare 30:2, 305-330. [CrossRef]

9. Botond Köszegi, Matthew Rabin. 2007. Reference-Dependent Risk Attitudes. American Economic Review 97:4, 1047-1073. [CrossRef]

10. Pavlo R. Blavatskyy. 2007. Stochastic expected utility theory. Journal of Risk and Uncertainty 34:3, 259-286. [CrossRef] 